\title{
Ozone pollution during stratosphere-troposphere exchange events over equatorial Africa
}

\author{
K. Ture \& G. Mengistu Tsidu \\ Department of Physics, Addis Ababa University, Ethiopia
}

\begin{abstract}
Both natural factors such as thunderstorm events and anthropogenic activities contribute to very high ozone production. On the flight route from Johannesburg to Vienna enhanced ozone and relative humidity spikes were observed by MOZAIC (Measurements of Ozone by Airbus In service airCraft). MOZAIC recorded high resolution in-situ ozone and relative humidity at a flying altitude of $250-200 \mathrm{hPa}$ at equatorial Africa. This area is one of the lightning hot spot regions of the world. We report introduction of enhanced ozone of stratospheric origin into the troposphere during two events and the resulting pollution. Vertical cross-section of potential vorticity over the region of interest showed high PV intrusion below the tropopause level. Both OLR (Outgoing longwave radiation) and vertical wind have indicated presence of strong convection. Cloud water content transport and high latent heat have confirmed the existence of thunderstorm activity coupled to PV intrusion. The two distinct events are characterized by very low ozone within the thunderstorm cloud and very high ozone of stratospheric origin outside the thunderstorm cloud. The events have produced ambient air pollution
\end{abstract}

Keywords: thunderstorm, scavenging, pollution, ozone spikes, PV intrusion.

\section{Introduction}

Ozone has different impacts depending on where it resides. Stratospheric ozone, where approximately $90 \%$ of the atmospheric ozone is found, prevents the sun's ultraviolet radiation reaching the surface of the earth. In the troposphere, ozone is direct green house gas [1] while in the boundary layer, it is a pollutant, which has harmful effect on human, animal and crops. The health impact of ozone depends 
on the age group and health status of individuals. Since there is no discernible threshold below which no adverse health effects occur, no level would eliminate all risk. Thus, a zero risk standard is not possible.

However, the current WHO (World Health Organization) AQG (Air quality guidelines) in the year 2000 for $\mathrm{O}_{3}$ provide a guideline value of $120 \mu \mathrm{g} / \mathrm{m}^{3}$ $(60 \mathrm{ppb})$, based on controlled human exposure studies, for a maximum 8-hour concentration. The AQG also provides two concentration-response tables, one for health effects estimated from controlled human exposure studies and one from epidemiological studies. No guideline for long-term effects was provided. Since the time these guidelines were agreed, there is sufficient evidence for their reconsideration. Issues to be considered are: the averaging time(s) for the shortterm guidelines and their associated levels, the concentration-response functions used in the tables, the outcomes included in the concentration-response tables, whether a long-term guideline and/or complementary guidelines (e.g. restricting personal activity) should be adopted [2]. With regards to the sources of ozone at a given area; it is determined by transportation and/or in-situ production by different mechanisms.

Photochemical production is the dominant source of ozone in the stratosphere. In the troposphere, ozone is produced from biomass burning, natural emission from vegetation and soil, lightning, NOx emissions, and other anthropogenic sources such as emissions related to the combustion of fossil-fuel for energy, industrial, transport and domestic uses. Over the tropics, Africa is an important reservoir of ozone precursor sources allowing ozone to build up through active photochemistry exacerbated by high solar radiation. Africa contributes a significant amount to the global emissions from the first three categories, while emissions from fossil fuel combustion are important only on the regional scale.

Regener [3] and Junge [4] consider the stratosphere to be the main source from which ozone enters the troposphere via tropopause exchange processes. Ozone is transported from the lower stratosphere into the upper troposphere through tropopause folding $[5,6]$ and is exchanged with the troposphere via diabatic processes and turbulent diffusion [7], mixing processes and convective erosion during the breakup of stratospheric filaments $[8,9]$.

The most important sources of ozone precursors over equatorial Africa are biomass burning, biogenic and lightning. African biomass burning activities, generally categorized as savanna, forest and agricultural waste burning, are driven by the "slash and burn" agricultural practices that take place during the dry seasons (late November to early March) in the northern hemisphere (NH), and July to October in the southern hemispheric (SH). The dynamic processes allow redistribution of such emissions on a more global scale. During the TRACE-A campaign, plumes loaded with high $\mathrm{O}_{3}$ over the Atlantic were attributed to biomass burning emissions from Africa. More recently high $\mathrm{CO}$ mixing ratios over the Indian Ocean have been attributed to African biomass burning [10]. Thunderstorms inject NOx mainly into the relatively clean upper troposphere. Measurements of $\mathrm{O}_{3}$ in clouds indicate that both production and loss mechanisms exist. Locally within the cloud the concentrated NO reacts with 
ambient $\mathrm{O}_{3}$ to produce $\mathrm{NO}_{2}$ which reduces the $\mathrm{O}_{3}$ abundance accordingly. Lightning NOx is also responsible for a large fraction of the $\mathrm{O}_{3}$ produced in the troposphere [11].

Dickerson et al. [12] measured enhanced mixing ratios inside a cloud compared to the boundary layer value; Poulida et al. [13] measured high $\mathrm{O}_{3}$ near but not within a thunderstorm anvil. Both attributed this effect to intrusion of stratospheric air. Hauf et al. [14] detected a drop in $\mathrm{O}_{3}$ on entering the anvil core of a thunder storm cloud. Similar measurements by Ridley et al. [15] and Huntrieser et al. [16] also showed no systematic increase of in-cloud $\mathrm{O}_{3}$ concentrations. In contrast, Drapcho et al. [17] found a correlation between a decrease in $\mathrm{O}_{3}$ and an increase in $\mathrm{NO}_{2}$ caused by the production of $\mathrm{NO}$, followed by its reaction with $\mathrm{O}_{3}$. Recent laboratory studies of arc discharges also indicate a large ratio of $\mathrm{NO} / \mathrm{NO}_{2}$ and minimal $\mathrm{O}_{3}$ production [18]. According to Price [19] and Price and Asfur [20], equatorial Africa is one of lightning hot spot regions of the world. Marufu et al. [21] showed that $27 \%$ of the troposphere $\mathrm{O}_{3}$ abundance observed over Africa is caused by lightning induced nitrogen oxides (LNOx).

On few occasions of several MOZAIC measurements during the period 199697, ozone and relative humidity spikes were observed at equatorial Africa. The main focus of this work is to investigate the causes and sources for the enhancements. These enhancements are spikes, covering very small region and dispersed. We used ozone records of GOME (Global Ozone Mapping Experiment) in the troposphere during this time from the European Centre for Medium-Range Weather Forecasts (ECMWF)-ERA-interim as complimentary information. Two processes were clearly distinguished: stratospheric intrusion and thunderstorm activities happening within the same time frame, between 12 and 18 UTC. The paper is structured as follows. In Section 2, the data and methodology used in this work will be presented. Section 3 gives a brief description of both MOZAIC ozone and relative humidity spike observations. In Section 4, the existence of stratospheric and troposphere exchange during the events is presented. Also mechanism of transport of ozone of stratospheric origin down to the ground level is discussed. Finally, the conclusion will be presented in Section 5.

\section{Data and methodology}

Measurements of ozone in the MOZAIC program are taken every four seconds from take-off to landing. Based on the dual-beam UV absorption principle (Model 49-103 from Thermo Environment Instruments, USA), the ozone measurement accuracy is estimated to be $\pm[2 \mathrm{ppbv}+2 \%]$ [22]. From the beginning of the program in 1994, the measurement quality control procedures have remained unchanged to ensure that long-term series are free of instrumental artefacts. Instruments are laboratory calibrated before and after the flight periods, the duration of which is generally 12 to 18 months. The laboratory calibration is performed with a reference analyzer which is periodically cross checked at the National Institute of Standards and Technology in France. Additionally during 
the flight operation period, the zero and the calibration factor of each instrument are regularly checked using a built-in ozone generator. Furthermore, comparisons are made between aircraft when they fly close in location and time, which happen several times a month. Ozone measurements from the MOZAIC program were validated by comparisons with the ozone sounding network [23]. Data are recorded from aircraft take-off to landing, providing vertical profiles and cruise data between 8 and $12.5 \mathrm{~km}$ altitude.

In this study only cruise data between $20 \mathrm{~S}-20 \mathrm{~N}$ were considered. In addition to MOZAIC data records, additional data such as potential vorticity, $\mathrm{O}_{3}$ mass mixing ratio, vertical and meridional wind fields, cloud cover, cloud liquid water content and relative vorticity data derived from ECMWF ERA-intrim data set were used to investigate the observed spikes during the events. The ERA-intrim data sets are given on a horizontal resolution of $1.5 \times 1.5$ degree and variable vertical resolution in pressure level with a 6-hourly analysis frequency. The vertical levels used for this analysis were partitioned in such a way that there are 6 levels within 900-775 hPa layer at an interval of $25 \mathrm{hPa}, 11$ levels within 750$250 \mathrm{hPa}$ layer at an interval of $50 \mathrm{hPa}, 7$ levels within 250-100 hPa layer at interval of $25 \mathrm{hPa}, 2$ levels at 70 and $50 \mathrm{hPa}$ each. The ERA-Interim data assimilation has T255 horizontal resolution, better formulation of background error constraint, reprocessed ozone profiles from GOME data from the Rutherford Appleton Laboratory from 1995 onwards and CHAMP GPS radio occultation measurements, reprocessed by UCAR. ERA-Interim uses mostly the sets of observations acquired for ERA-40, supplemented by data for later years from ECMWF's operational archive. EUMETSAT provided reprocessed winds and clear-sky radiances from Meteosat-2 (1982-1988) for ERA-40 and has reprocessed later Meteosat data for ERA-Interim [24]. The latent heat data set was retrieved from Mirador, Goddard earth sciences data and information center. Mirador contains a series of land surface parameters simulated from the Common Land Model (CLM) V2.0 model in the Global Land Data Assimilation System (GLDAS). The data are in 1.0 degree resolution and range from 1979 to the present. The temporal resolution is 3-hour [25]. The pressure and temperature profiles used to identify tropopause level, based on the methodology proposed in reference [26], were obtained from NASA Goddard Space Flight Center's Laboratory for Atmospheres.

\section{MOZAIC ozone and relative humidity observations}

$\mathrm{O}_{3}$ volume mixing ratio of exceeding $100 \mathrm{ppbv}$ were observed in very few MOZAIC flights during 1996-97 over the equatorial Africa region (20 S-20N) within $250-200 \mathrm{hPa}$ altitude range. The enhancements are shown in both panels of Fig. 1. This altitude level is below tropopause level marked by black cross lines shown in Fig. 2. High relative humidity at this cruise level over the region of elevated $\mathrm{O}_{3} \mathrm{VMR}$ is also observed. The question needs to be answered is then from where the high $\mathrm{O}_{3} \mathrm{VMR}$ of up to $190 \mathrm{ppbv}$ at 21 UTC originates. To answer this question, analysis of 5 days back trajectory on isentropic surfaces from online NOAA HYSPLIT was made. Then the observed ozone enhancement 


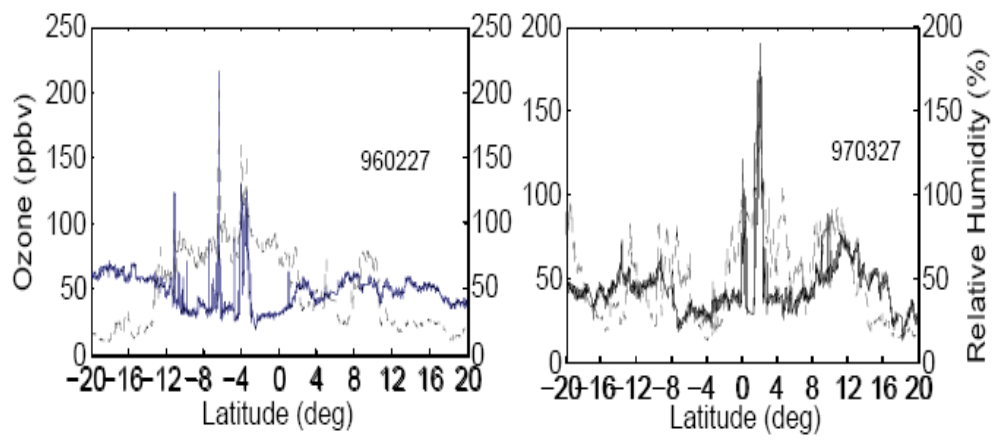

Figure 1: $\quad$ MOZAIC cruise ozone (solid line) and relative humidity (dash line) spikes observed on 27 February 1996 and 27 March 1997.
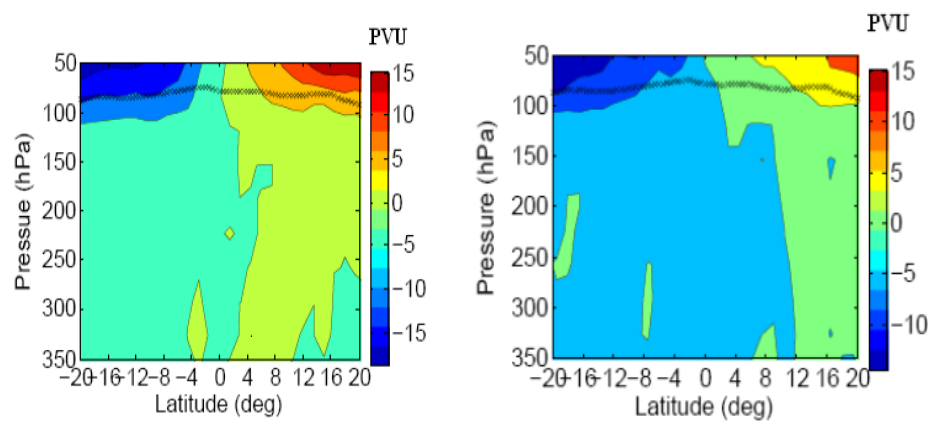

Figure 2: Potential vorticity vertical cross section at $25.5 \mathrm{E}$ between $20 \mathrm{~S}$ $20 \mathrm{~N}$ on 27 February 1996 (left panel) and 27 March 1997 (right panel) at 18 UTC. (The black cross-marks indicate tropopause level).

was traced along the trajectory and matched with SAGE ozone record (not shown) to determine whether horizontal transport contributed to the enhancement or not. The result of this analysis indicates that this air mass in the five days period had not encountered $\mathrm{O}_{3}$ rich air mass of similar concentration before 21 UTC. The other possible source of $\mathrm{O}_{3}$ rich air mass is stratospheric intrusion. Since the relative humidity content of the stratosphere is very low in addition to stratospheric intrusion there has to be other physical process happening in conjunction with stratospheric intrusion in the troposphere. Thunderstorm activity would be one of the most likely events that could produce high relative humidity record in the order of $100 \%$ in the vicinity of high ozone observation.

To determine whether this is the case or not, we have investigated potential vorticity, vertical velocity, $\mathrm{O}_{3} \mathrm{VMR}$, OLR, cloud cover, cloud liquid water content and latent heat flux data set of the same day. 


\section{Results and discussion}

To address the premises outlined above, first we investigated the existence of stratospheric intrusion at the area of the flight prior to the plane traversing the route. The two events occurred during 222030 -222454 UTC on 27 March 1997 and 213832-214716 UTC on 27 February 1996. Therefore we used ECMWF data at 12 and 18 UTCs ahead of the events. The potential vorticities for 27 February 1996 and 27 March 1997 at 18 UTC are depicted in Figure 2. High potential vorticity value greater than $2 \mathrm{PVU}$ is shown well below the tropopause marker in both panels of figures. This shows the existence of stratospheric intrusions which are capable of inducing high concentration ozone of stratospheric origin to the troposphere.

Secondly we investigated the existence convective air movement during this time. For this vertical wind (not shown here) and OLR values with in this time frame (12-18 UTC) were checked. OLR which is a proxy of deep convection for 27 February 1996 is shown in Figure 3 (right panel). Both vertical wind fields and OLR values for both days show the existence convection. Since no lightning data available during this time, we have used additional proxy parameters, such as cloud cover, cloud liquid water content and latent heat, which are indicators of the existence of thunderstorm activity. Nearly overcast cloud cover was observed at both 12 and 18 UTC (not shown) with higher values being at 12 UTC.
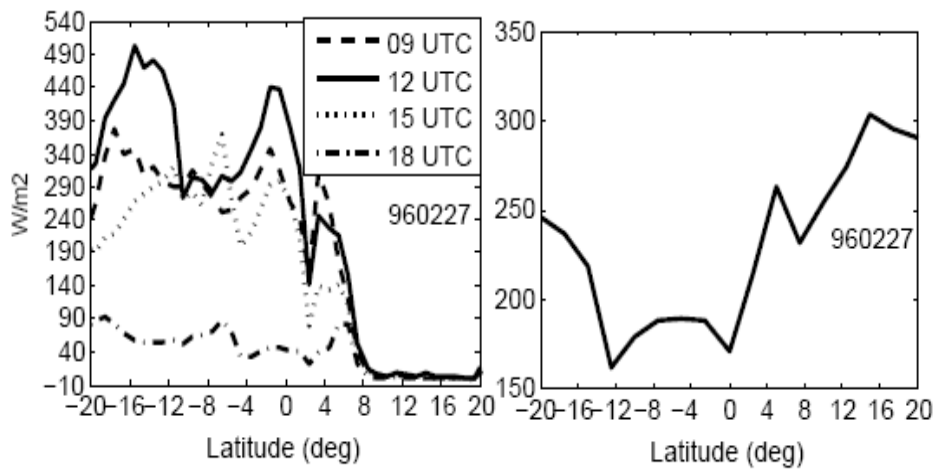

Figure 3: Latent heat (left panel) and OLR (right panel) on 27 February 1997.

Thunderstorm is associated with release of very high latent heat. On 27 February 1996, very strong latent heat in the region of cloud cover was observed. For instance, at $15.5 \mathrm{~S}$, the latent heat records at $09,15,12$ and $18 \mathrm{UTC}$ were $342.52,502.50,267.5,57.38 \mathrm{~W} / \mathrm{m}^{2}$ respectively (see Figure 3 , left panel). Again for the 27 March 1997, the latent heat flux shows similar features (not shown here). From these records it is apparent that thunderstorm dissipation likely occurred between 12 and 15 UTC because the heat flux grew from 09 to 12 UTC 

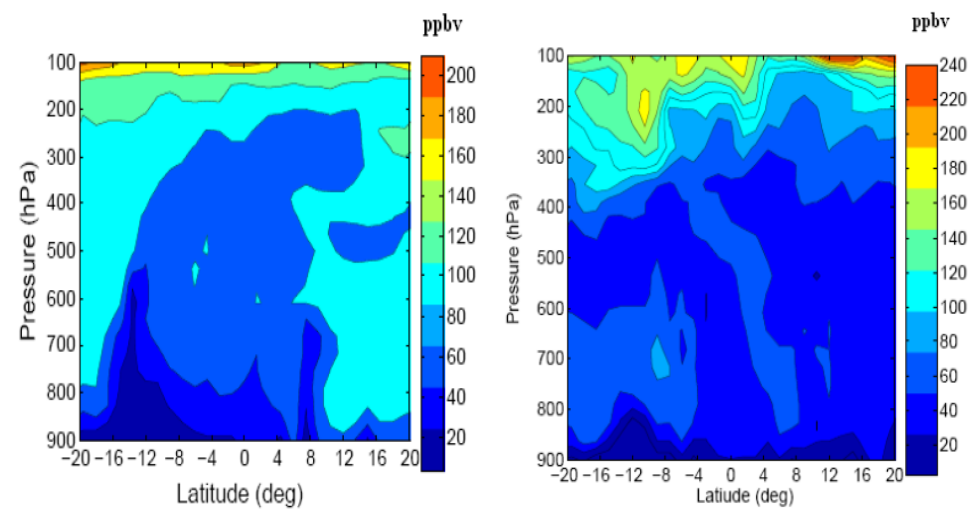

Figure 4: Ozone vertical cross section at 25.5 E on 27 February 996 (left panel) and 27 March 1997 (right panel) at 18 UTC.

and then decreased in between 12 and 15 UTC. In addition cloud liquid water transport, another indicator of thunderstorm activity. Observation of cloud liquid water content during both days at 12 and 18 UTC shows a clear ascent of cloud liquid water content during 18 UTC. According to Price and Asfur [20], equatorial Africa is one of the three thunderstorm hot spot regions (South America, Africa, and Southeast Asia) where most thunderstorm events take place around 14.00 UTC. Therefore our observations are in agreement with previous finding.

The vertical ozone mass mixing ratio profile is shown in Figure 4 (for clarity the altitude is restricted to $900-100 \mathrm{hPa}$ layer). During thunderstorm, electrical current causes the split in the oxygen molecules to atomic oxygen then further reaction of oxygen atom with oxygen molecule produces ozone. Ozone produced by this mechanism is very low. The lightning event also favors high nitrogen oxide (NO) production. NO reacts with ozone which leads to the production of nitrogen dioxide $\left(\mathrm{NO}_{2}\right)$ which is manifested in a decrease of $\mathrm{O}_{3}$ concentration. The net result is reduction of ozone within the thunderstorm cloud. Two clearly identified ozone events are shown in both panels of Figure 4. Very low ozone concentration in the region of cloud cover shows scavenging during both events over the whole equatorial latitudes. However, significant $\mathrm{O}_{3}$ VMR loss were confined to latitude bands of 5-16 S, 7-8 N on 27 February 1996 and 8-16 S on 27 March 1997. Theses regions were also sites of intense thunderstorm activity as revealed by proxy parameters.

On the other hand, during both MOZAIC observations and GOME data, enhanced $\mathrm{O}_{3}$ VMR was detected at upper troposphere. These were associated with PV intrusions. As discussed in the preceding paragraphs, part of the intruded stratospheric $\mathrm{O}_{3}$ VMR was able to descend down to boundary layer over the cloud free regions. 


\section{Conclusions}

Enhanced MOZAIC ozone and relative humidity spikes observed over equatorial Africa in the year 1996-97 have been analyzed. Stratospheric intrusion coupled to thunderstorm activity found to be the key physical process that attributed to spiky $\mathrm{O}_{3}$ VMR and relative humidity. Potential vorticity values exceeding 2 PVU observed below the tropopause level confirms stratospheric intrusion. The vertical air movement, OLR value, very high latent heat release, cloud liquid water transport indicate the existence of thunderstorm activity during the PV intrusion.

ECMWF ERA-interim ozone data were used to investigate the possible ozone distribution within the troposphere during these two dynamical events. Very low ozone of the order about 20 ppbv within the thunderstorm cloud was observed during these events. The low ozone level observed within the thunderstorm cloud is in agreement with previous reports. The other observed feature was very high ozone of stratospheric origin ( $>200 \mathrm{ppbv}$ ) over the upper equatorial troposphere during both observations. Our analyses have revealed that these were associated with PV intrusions. The intruding stratospheric ozone was able to make its way down to boundary layer outside the thunderstorm cloud. These processes have resulted in ambient air pollution with $\mathrm{O}_{3}$ VMR exceeding the proposed WHO guideline limit of $60 \mathrm{ppbv}$.

\section{References}

[1] Prather, M. \& Ehhalt, D., 2001. Atmospheric Chemistry and Greenhouse Gases in Climate Change 2001: The Scientific Bases, (Eds.) by J. T. Houghton et al., Cambridge University Press, Cambridge.

[2] Report on a WHO Working Group, Health Aspects of Air Pollution with Particulate Matter, Ozone and Nitrogen Dioxide. Bonn, Germany 13-15, 2003.

[3] Regener, V. H., Vertical flux of atmospheric ozone, J. Geophys. Res., 62, pp. 221-228, 1957.

[4] Junge, C. E., Global ozone budget and exchange between stratosphere and troposphere. Tellus, 14, pp. 363-377, 1962.

[5] Danielsen, E. F., Stratospheric-tropospheric exchange based on radioactivity, ozone and potential Vorticity. J. Atmos. Sci., 25, pp. 502528, 1968.

[6] Danielsen, E. F., Hiskind, R. S., Gaines, S. E., Sachse, G. W., Gregory, G. L., and Hill, G. F., Three-dimensional analysis of potential vorticity associated with tropopause folds and observed variations of ozone and carbon monoxide. J. Geophys. Res., 92, pp. 2103-2111, 1987.

[7] Lamarque, J. F. and Hess, P. G., Cross-tropopause mass exchange and potential vorticity budget in a simulated tropopause folding. J. Atmos. Sci., 51, pp. 2246-2269, 1994. 
[8] Appenzeller, C., Holton, J. R., and Rosenlof, K.H., Seasonal variation of mass transport across the tropopause, J. Geophys. Res., 101(D10), pp.15071-15 078, 1996.

[9] Gouget, H., Vaughan, G., Marenco, A., and Smit, H. G. J., Decay of a cutoff low and contribution stratosphere-troposphere exchange. Q. J. R. Meteorol. Soc., 126, pp. 1117-1141, 2000.

[10] Sauvage, B., Thouret, V., Cammas, J.-P., Gheusi, F., Athier, G., and Nédélec, P., Tropospheric ozone over Equatorial Africa: regional aspects from the MOZAIC data. Atmos. Chem. Phys. Discuss., 4, pp. 3285-3332, 2004.

[11] Grewe, V., Impact of climate variability on tropospheric ozone. Sci. Total Environ., 374, pp.167-181, 2007.

[12] Dickerson, R. R. et al., Thunderstorms: An important mechanism in the transport of air pollutants. Science, 235, pp. 460-464, 1987.

[13] Poulida, O. et al., Stratosphere-troposphere exchange in a midlatitude mesoscale convective complex 1. Observations. J. Geophys. Res., 101(D3), pp. 6823-6836, 1996.

[14] Hauf, T. et al., Rapid vertical traces gas transport by an isolated multitude thunderstorm, J. Geophys. Res., 100(D11), pp. 22957-22970, 1995.

[15] Ridley, B. A. et al., Distribution of NO, NOx, NOy, and $\mathrm{O} 3$ at $12 \mathrm{~km}$ altitude during the summer monsoon season over New Mexico, J. Geophys. Res., 99(D12), pp. 25519-25534, 1994.

[16] Huntrieser, H. et al., Transport and production of NOx in electrified thunderstorms: Survey of previous studies and new observations at midlatitudes, J. Geophys. Res., 103(21), pp. 28247-28264, 1998.

[17] Drapcho, D. L. et al., Nitrogen fixation by lightning activity in a thunderstorm. Atmos. Environm., 17(4), pp. 729-734, 1983.

[18] Wang, Y. et al., Nitric oxide production by simulated lightning: Dependence on current, energy, and pressure. J. Geophys. Res., 103(D15), pp. 19149-19159, 1998.

[19] Price, C., Lightning Sensors for Observing, Tracking and Now Casting Severe Weather. Sensors, 8, pp.157-170, 2008.

[20] Price, C., and Asfur, M., Can Lightning Observations be used as an Indicator of Upper-Tropospheric Water Vapor Variability? American Metrological Society, pp. 291-298, 2006.

[21] Marufu, L., Dentener, F., Lelieveld, J., Andreae, M. O., and Helas, G., Photochemistry of the African troposphere: Influence of biomass-burning emissions, J. Geophys. Res., 105(2248) , pp. 14513-14530, 2000.

[22] Thouret, V., Marenco, A., Nédélec, P., and Grouhel, C., Ozone climatologies at 9-12 km altitude as seen by the MOZAIC airborne program between September 1994 and August 1996, J. Geophys. Res., 103(25), pp. 653-679, 1998a.

[23] Thouret, V., Marenco, A., Logan, J. A., Nédélec, P., and Grouhel, C., Comparisons of ozone measurements from the MOZAIC airborne program and the ozone sounding network at eight locations, J. Geophys. Res., 103(25), pp. 695-720, 1998 b. 
[24] ECMWF, Website, uk http://wcrp.ipsl.jussieu.fr/Workshops/Reanalysis 2008/Documents/V1- 102 ea.pdf.

[25] Mirador, Website, NASA Goddard, http://mirador.gsfc.nasa.gov.

[26] McCalla, C., Objective Determination of the Tropopause Using WMO Operational Definitions, U.S. Department of Commerce National Oceanic and Atmospheric Administration National Weather Service Metrological Center, October 1981. 